\title{
Application of multi-sensor satellite remote sensing for determining distribution and movement of Pacific saury Cololabis saira
}

BAMBANG SEMEDI ${ }^{1}$ SEI-ICHI SAITOH, ${ }^{1}$ KATSUYA SAITOH, ${ }^{2}$ AND KUNISABURO YONETA ${ }^{1}$

'Graduate School of Fisheries Sciences, Hokkaido University, Hakodate, Japan (bambang@salmon.fish.hokudai.ac.jp), and ${ }^{2}$ Japan Fisheries Information Service Center, Japan.

SUMMARY: A time series of DMSP-OLS (Defense Meteorological Satellite Program - Operational Linescan System) satellite image in autumn from 1994 to 1998 and SeaWiFS (Sea-viewing Wide Field-of-view Sensor)- Ocean Color image data of 1997 and 1998 were observed to study distribution and movement of Pacific saury Cololabis saira off Sanriku, Northwestem North Pacific. Daily, 10-days and annual OLS visible-near infrared images were analyzed to determine fishing locations of Pacific saury fisheries. This study provides comprehensive examination of distribution and movement of Pacific saury in relation to satellite image of DMSP-OLS derived fishing fleet light. Pacific saury fishing locations distribute and move according to remarkable changes of environmental conditions especially in the waters of northwestem north Pacific. Our analysis suggests that most of the fishing location of Pacific saury distlbuted in the colder side of Oyashlo fronts and cold streamers where SST (sea surface temperature) ranged from $4.5^{\circ} \mathrm{C}$ to $18^{\circ} \mathrm{C}$. Two ranges chlorophyll concentration, from $0.1 \mathrm{mg} \mathrm{m}^{-3}$ to $0.5 \mathrm{mg} \mathrm{m}^{-3}$ and from $7.0 \mathrm{mg} \mathrm{m}^{-3}$ to $7.5 \mathrm{mg} \mathrm{m}^{-3}$, mostly observed in the locations of fishing fleet lights.

\section{KEYWORDS: DMSPI OLS, Pacific saury, Fishing Fleet Light and Sanriku}

\section{INTRODUCTION}

In Japan, Pacific saury (Cololabis saira) has long been exploited in particular seasons of the year in various waters. Since 1949, the saury fishermen employed stick-held dip net, known as bouke ami in Japanese language, which is equipped with lights to attract the fish." In general, Pacific saury migrates to the Oyashio area while growing up from spring to the summer. Moreover, they migrate from the Oyashio area to the south through the Oyashio front in the autumn for spawning. ${ }^{2}$

Recently, satellite remote sensing is an important tool as a means of obtaining synoptic measurement of the ocean. Satellite data have been applied to study the relation between oceanographic conditions and the distribution of pelagic fishes. ${ }^{3)}$ Using the OLS-VNIR (Operational Linescan Systemvisible-near infrared) band of DMSP (Defense Meteorological Satellite Program) satellite, it is possible to detect clouds illuminated by moonlight, and lights from cities, towns, industrial sites, gas flares, and ephemeral events, such as fires and lightning-illuminated clouds. ${ }^{4)}$ Since fishing boats of saury fishery are equipped with light during fishing activities, the fishing fleet lights can be identified by night light images generated by the DMSP-OLS sensor. Regarding DMSP-OLS satellite image observations, Cho et $\mathrm{al}^{\text {s) }}$ reported a clear relationship between the locations of fishing fleet lights and the SST distribution was observed in an overlaid image OLS-VNIR image and OLS-TIR (Thermal Infrared) image. Many fishing fleets were located at the cold side of the boundary area between warm currents and cold currents. Objective of this study is to understand the distribution and movement of Pacific saury and its environmental factors off Sanriku, northwestern north Pacific using multi-sensor satellite remote sensing

\section{DATA AND METHODS}

The data set on locations of fishing fleet lights used in the present study was generated from DMSP-OLS visible images in autumn from 1994 to 1998. Distribution of Oyashio fronts and SST (sea surface temperature) were observed using DMSP-OLS thermal infrared. We employed TeraScan and, Erdas Imagine and ArcView3 as a GIS tool to make overlaid images. Figure 1 shows a schematic diagram of the DMSP-OLS data processing. The OLS raw 
data were transformed into Mercator projections to obtain images with a resolution of $1.1-\mathrm{km}$ off Sanriku. Each pixel of DMSP-OLS thermal infrared images contained a DN (Digital Number) value between 0 and 255. Values between 0 and 254 were converted to SST values with the equation:

$$
\operatorname{SST}\left({ }^{\circ} \mathrm{C}\right)=0.0934 \mathrm{DN}+2.0332
$$

We used SeaWiFS (Sea-viewing Wide Field-of-view Sensor)- Ocean Color image data of 1997 and 1998 to observe chlorophyll-a concentration. Fishing positions of QRY data provided by the JAFIC (Japan Fisheries Information Service Center) were plotted on overlaid image between the SST images and the fishing fleet light images to examine the relationship between the SST and fishing locations. The relationship between fishing locations and chlorophyll-a concentration were observed using overlaid images of the fishing fleet light of DMSP-OLS and SeaWiFS -Ocean Color.

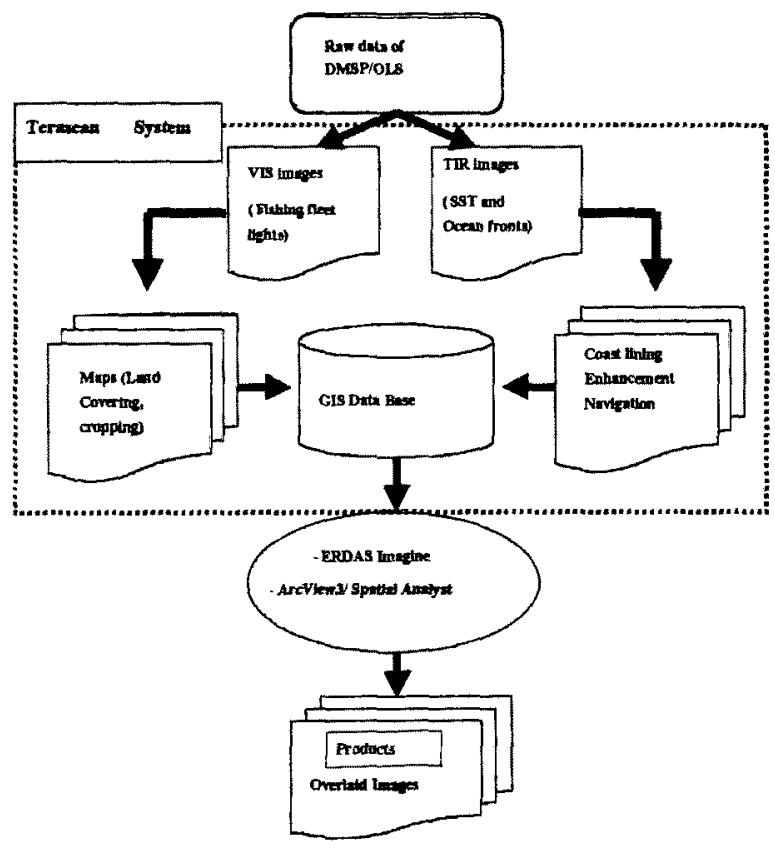

Fig. 1 Illustration of DMSP-OLS image processing.

The OLS-VNIR images contain the lights from the saury fishing fleets and squid fishing fleets. We tried to separate them based on their distributions and environmental conditions. Researchers have reported that the fishing grounds of Pacific saury are usually located in cold Oyashio waters and cold filaments or cold streamers. ${ }^{6,3)}$ Pacific saury migrate with the cold streamers of the Oyashio around KWCRs (Kuroshio Warm Core Rings), and the fishing ground form on the colder side of the front. Squids, however, move into the warm streamers, and the fishing ground forms in the warmer water areas inside the KWCRs. We, then, assumed that the fishing grounds of Pacific saury did not occur inside warm water area, such as the TWCG (Tsugaru Warm Current Gyre). In this case, the fishing fleet lights located inside TWCG and KWCRs were neglected.

\section{RESULT AND DISCUSSION}

Daily overlaid image of the OLS-VNIR in Figure 2 shows that the short-term variations of the fleet distribution. On November 4, 1994, the fleets remained in the area around $40^{\circ} 30^{\prime} \mathrm{N}$ and $144^{\circ} 30^{\prime} \mathrm{E}$. On November 7, 1994, the fleet had already moved up to $100 \mathrm{~km}$ southeastward at a speed of about 116 $\mathrm{cm} / \mathrm{s}$. On November 8, 1994, the fleet extended offshore up to $10 \mathrm{~km}$ from the fleet of November 7,1994 . However, the number of the fishing fleet lights had decreased. On November 9, 1994, the fleet moved up to $45 \mathrm{~km}$ offshore at a speed of about 52 $\mathrm{cm} / \mathrm{s}$. The offshore shift of the fleets, especially from November 8 to November 9,1994 , was caused by a shift of the front area between the KWCR-93 ${ }^{8,9)}$ and cold Oyashio waters. Ten-days basis overlaid image (Figure 2) shows that in early fishing season (from August to September), concentration of fishing fleet lights were in southeastem side of Hokkaido and moved southward to aggregate along the Sanriku coast and off Sanriku. At the end of saury fishing season during November and December, the fishing fleets were seen close to the shore of Sanriku and Joban with the southernmost fleets around latitude $36^{\circ} \mathrm{N}$ longitude $141^{\circ} \mathrm{E}$.

According to former studies, Uda, ${ }^{10}$ Hughes, ${ }^{11)}$ Tameishi, ${ }^{6)}$ Sablin and Pavlychev ${ }^{12)}$ reported the fishing grounds of Pacific saury are observed over wide SST range from $6.5^{\circ} \mathrm{C}$ to $18^{\circ} \mathrm{C}$. We constructed daily basis overlaid images of OLS-VNIR channel images, OLS-TIR channe! images, and daily fishing positions as shown in examples of Figure 3 to examine SST distribution on fishing locations. We found that most of the fishing fleet lights distributed in the colder side of the Oyashio fronts and cold streamers. Histogram of Figure 4 shows that the fishing fleets widely distributed in the areas where SST ranged from $4.5^{\circ} \mathrm{C}$ to $18^{\circ} \mathrm{C}$.

The overlaid image between the fishing fleet light images of the OLS-VNIR images and chlorophyll concentration image of the SeaWiFS as shown in examples on Figure 5 shows clearly the relationship between fishing location of Pacific saury and chlorophyll concentration. In the present study, we observed that fishing fleets were located in the 

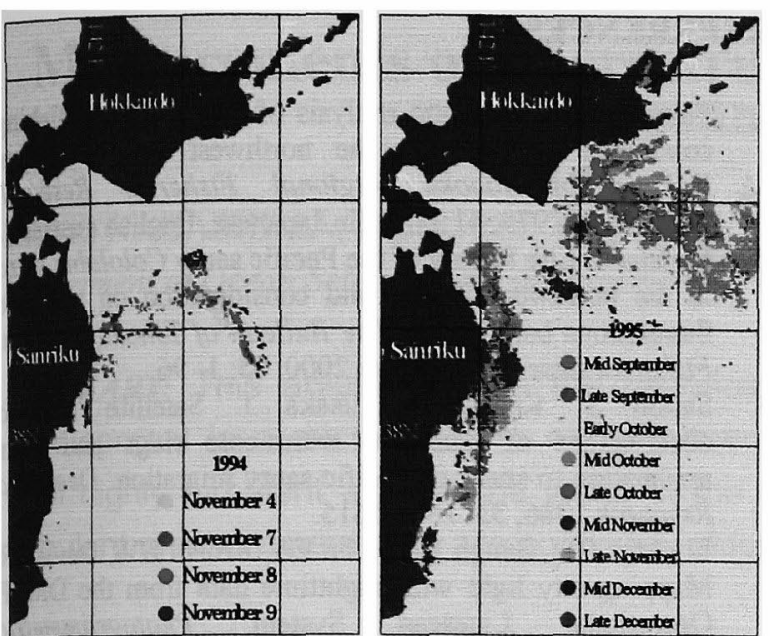

Fig. 2 Daily overlaid image of DMSP- OLS-VNIR sensor on November 1994 (left) and ten-days (right) overlaid image from mid September to late December 1995

Oyashio waters with relatively higher chlorophyll concentrations. Some fishing fleets were also seen in the waters with relatively lower chlorophyll concentration, around latitude $38^{\circ} \mathrm{N}$ and longitude $143^{\circ} \mathrm{E}$. Figure 6 shows that the fishing fleets widely distributed in the waters with chlorophyll concentration ranged from $0.1 \mathrm{mg} \mathrm{m}^{-3}$ to $9.5 \mathrm{mg} \mathrm{m}^{-3}$. Furthermore, we observed that the fishing fleets mostly located in both the waters with relatively lower chlorophyll concentration ranged from $0.1 \mathrm{mg}$ $\mathrm{m}^{-3}$ to $0.5 \mathrm{mg} \mathrm{m}^{-3}$ and the waters with relatively higher chlorophyll concentration ranged from $7.0 \mathrm{mg} \mathrm{m}^{-3}$ to $7.5 \mathrm{mg} \mathrm{m}^{-3}$. Moreover, higher abundance of the fishing fleets were observed in the waters with lower chlorophyll concentration range between $0.1 \mathrm{mg} \mathrm{m}^{-3}$ and $0.5 \mathrm{mg} \mathrm{m}^{-3}$.
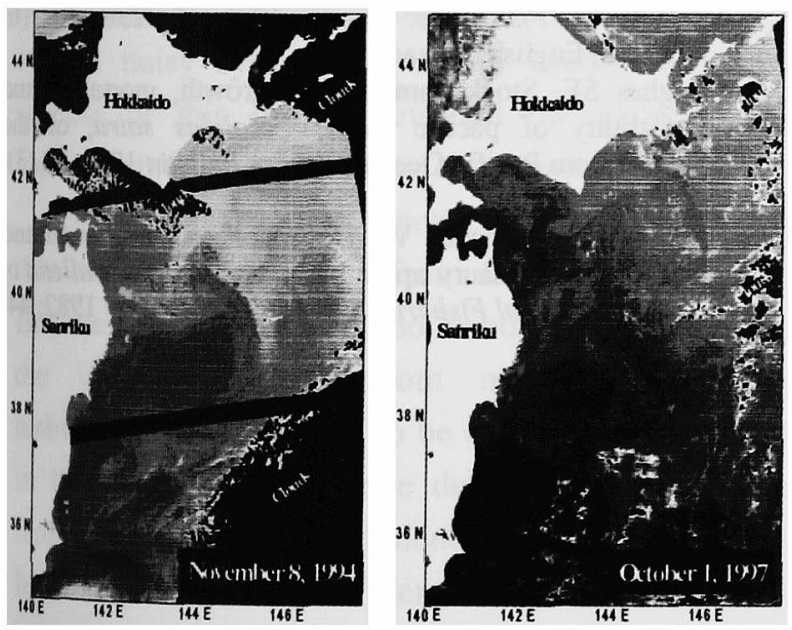

Fig. 3 Overlaid images of OLS-VNIR, OLS-TIR, and QRY-fishing positions on November 8, 1994 (left) and October 1, 1997 (right). Red points and yellow triangles represent the fishing fleet lights and fishing positions respectively.

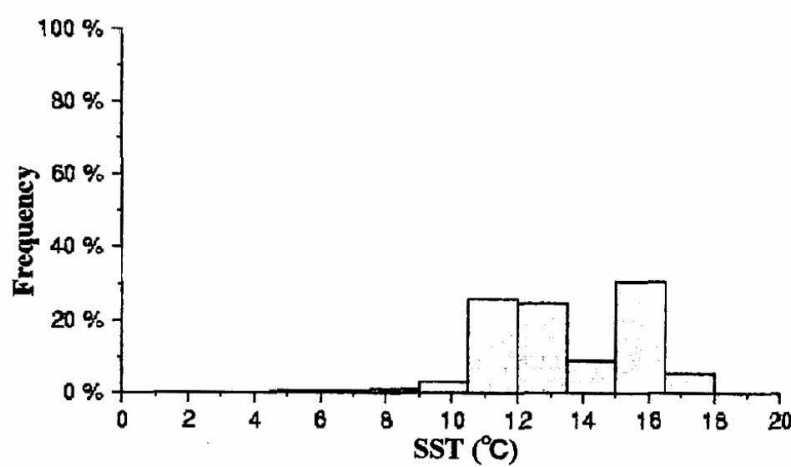

Fig. 4 Distribution of SST generated from the OLS-TIR image of 8 November 1994, 30 September 1995, 3 November 1996, 1 October 1997 and 29 October 1998 on the selected areas where both fishing fleet lights and fishing positions located.
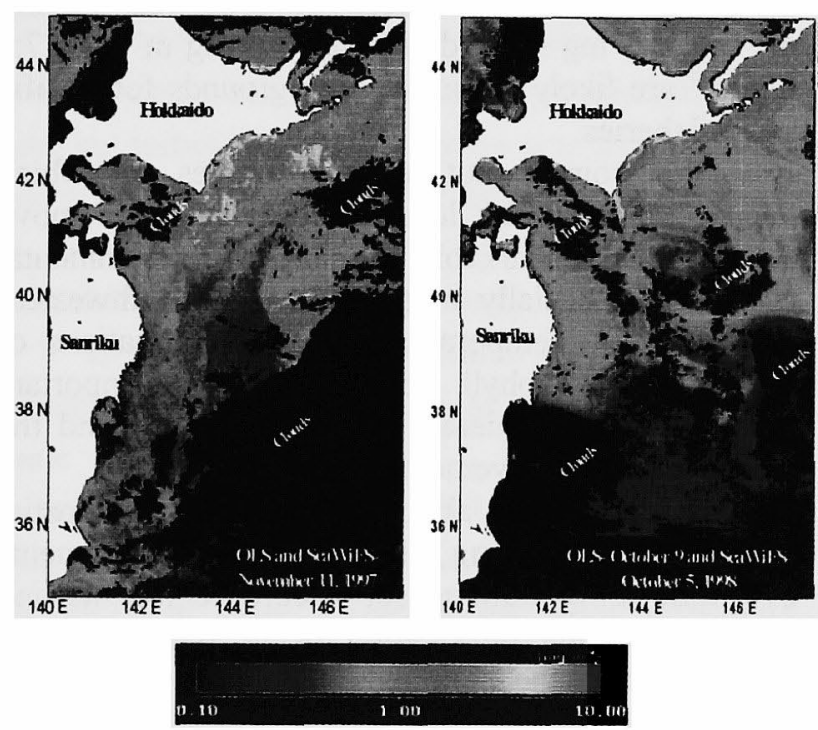

Fig. 5 Overlaid image between OLS-VNIR and SeaWiFS on November 11, 1997 (right). Overlaid image between OLS-VNIR on October 9, 1998 and SeaWiFS on October 5, 1998 (left). Red point represents the fishing fleet light.

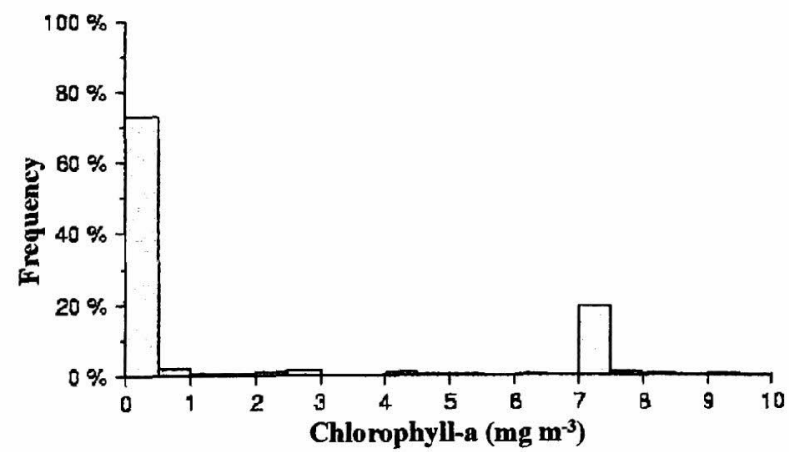

Fig. 6 Distribution of chlorophyll concentration generated from the SeaWiFS observed on October and November 1997; and October, November and December 1998 on the selected areas where fishing fleet lights located. 


\section{CONCLUDING REMARKS}

In the present study, we succeeded to determine distribution and movement Pacific saury using mainly DMSP-OLS satellite image. These results showed clearly the relationship between SST and fishing fleet light. Most of fishing locations occurred in the colder water of Oyashio and cold streamers where SST ranged from $4.5^{\circ} \mathrm{C}$ to $18^{\circ} \mathrm{C}$. This approach was also able to indicate the short-term change of fishing locations and the annual variability of fishing ground formation. These results might assist to understand that in early fishing season, Pacific saury aggregated in the southeastem of Hokkaido and they, then, gradually moved toward southward along the Sanriku coast, off Sanriku and the Joban coast. The waters areas with chlorophyll concentration between $0.1 \mathrm{mg}$ $\mathrm{m}^{-3}$ and $0.5 \mathrm{mg} \mathrm{m}^{-3}$ and between $7.0 \mathrm{mg} \mathrm{m}^{-3}$ and 7.5 $\mathrm{mg} \mathrm{m}^{-3}$ are likely a good fishing grounds for Pacific saury fisheries.

We pointed out some examples, in which Pacific saury fishing locations distribute and move according to remarkable changes of environmental conditions especially in the waters of northwestern north Pacific. Temporal and spatial fluctuations of SST and chlorophyll concentration are important factors to be considered in order to understand the distribution and movement of Pacific saury.

In future, the ability to visualize the spatial distribution of fishing fleets and their movements over time using multi-sensor satellite remote sensing might provide the information for the assessment and management of the exploited Pacific saury stocks.

\section{ACKNOWLEDGEMENTS}

We wish to express our sincere thanks to $\mathrm{Dr}$. Christopher D. Elvildge and Mr. David Serke, NGDC/NOAA for providing OLS data. SeaWiFS data were obtained from the NASA Goddard Distributed Active Archive Center. Use of these data is in accord with the SeaWiFS Research Data Use Term and Condition. This study was supported in part by Grant-in-Aid (10460079) from the Ministry of Education, Culture, Sports, Science and Technology. This work also partly supported by Sasagawa Scientific Research Grant from the Japan Science Society.

\section{REFERENCES}

1. Fukushima S. Synoptic analysis of migration and fishing conditions of saury in the northwest Pacific Ocean. Bulletin of Tohoku Regional Fisheries Research Laboratory 1979; 41:1-70. (In Japanese, English abstract).

2. Kosaka S. Life history of the Pacific saury Cololabis saira in the northwest Pacific and consideration on resource fluctuations based on it. The Bulletin of Tohoku National Fisheries Research Institute 2000; 63: 1-96.

3. Saitoh S, Kosaka S, Iisaka J. Satellite infrared observations of Kuroshio warm-core rings and their application to study of Pacific saury migration. Deep-Sea Research 1986; 33: 1601-1615.

4. Elvildge CD, Baugh KE, Kihn EA, Kroehl HW, Davis ER Mapping city light with nighttime data from the DMSP Operational Linescan System. Photogrammetric Engineering and Remote Sensing 1997; 63: 727-734.

5. Cho $K$, Ito R, Shimoda H, Sakata T. Fishing fleet lights and sea surface temperature distribution observed by DMSP/OLS sensor. Int. J. Remote Sensing 1999; 20 (1): 3-9.

6. Tameishi H: Fisheries detection using NOAA satellite. In: Murai S (ed). Applications of remote sensing in Asia and Oceania: environmental change monitoring. Asian Association on Remote Sensing, 1991 pp. 323-332.

7. Sugimoto $T$, Tameishi $H$. Warm-core rings, streamers and their role on the fishing ground formation around Japan. Deep-Sea Research 1992; 39 (1): 183-201.

8. Inagake D. Statistic of the Kuroshio warm-core ring migration by historical data from 1981 to July 1996 . The Bulletin of Tohoku National Fisheries Research Institute 1997; 59: 149-162.

9. Inagake D, Saitoh S. Description of the oceanographic condition off Sanriku northwestern Pacific, and its relation to spring bloom detected by the Ocean Color and Temperature Scanner (OCTS) images. Journal of Oceanography 1998; 54: 479-494.

10. Uda M. Fishing center of "Sanma" Cololabis saira(Brevoort), correlated with the head of Oyashio cold current. J. Fish. Soc. Japan 1936; 5: 236-238. (In Japanese, English abstract).

11. Hughes SE. Stock composition, growth, mortality, and availability of pacific saury, Cololabis saira, of the Northeastern Pacific Ocean. Fishery Bulletin 1974; 72 (3): 121-131.

12. Sablin VV, Pavlychev VP. Dependence of migration and catch of Pacific saury upon thermal conditions. Bulletin of Tohoku Regional Fisheries Research Laboratory 1982; 44: 109-116. 